UDC 811.111'37

$81^{\prime} 11: 165$

Kasia M. Jaszczolt

University of Cambridge, UK

\title{
VARIETIES OF DEFAULTS
}

\begin{abstract}
It can hardly be contested that in the process of utterance interpretation some readings are more salient than others. The problem arises when the relative salience of these readings is to be accounted for by means of such concepts as 'pragmatic inference' or 'default meaning'. In this paper I discuss various versions of the so-called 'default model' of utterance interpretation and identify characteristic features of defaults that are shared by some of the default views but rejected by others. Next, I propose a classification of 'default meanings' founded on the name of the source of the salient interpretation and suggest a semantic/pragmatic framework in which such types of defaults can be utilised. I conclude that, seen in the light of the concept of default meaning arrived at in this paper, the polarisation of the debate into the supporters and critics of defaults is largely terminological.
\end{abstract}

\section{Introduction}

It can hardly be contested that when the speaker utters (1), the inference in (2) normally follows.

(1) Ned Kelly lived in Australia or New Zealand.

(2) The speaker does not know for certain that Ned Kelly lived in Australia.

But the process through which the hearer arrives at meanings such as that in (2) has been the subject of an ongoing controversy between those who remain closer to Grice's (1975) concept of a generalized conversational implicature and defend them as salient, unmarked, 'presumed' meanings (Horn, e.g. 1984, 1988, 2004; Levinson 1987, 1995, 2000, also more recently Recanati 2003, 2004; Jaszczolt, e.g. 1999a, b, 2002, 2005, 2006), and those who attempt to classify them with context-dependent inferences 
(Sperber and Wilson 1995; Carston, e.g. 1988, 1998a, 2002a). However, the following contrast is evidently present:

Whatever the theoretical status of the distinction, it is apparent that some implicatures are induced only in a special context (...), while others go through unless a special context is present (...).

Horn (2004: 4-5)

This paper takes as its point of departure the first of the two orientations mentioned above. I reassess arguments in favour of such 'normal', 'typical' inferences and suggest that in order to obtain a coherent and cognitively adequate theory of salient interpretations, one has to postulate various types of 'default interpretations', each governed by its own principles and each contributing to the communicated information in its own particular way. As a by-product of this classification, the notion of 'default' will emerge considerably weakened. It is argued that the role of inference and context-dependence have to be reassessed in order to arrive at a plausible notion of salient interpretation. By way of a detailed reassessment of the types and properties of defaults, I will offer a proposal that falls mid-way between the radical defaults stance of presumptive meanings (Levinson 1995, 2000) and the accounts on which there are no such defeasible, presumed meanings, such as relevance theory (Sperber and Wilson 1995).

Before attempting a typology of default meanings, it is necessary to establish what exactly is meant by a default interpretation. There is considerable confusion in the literature concerning this term. In a nutshell, the differences in understanding of the term 'default' pertain to the acceptance, or the lack thereof, of the following properties: (i) cancellability (defeasibility) of default interpretations, (ii) their availability prior to any conscious inference; and (iii) the shorter time required for their arrival as compared with interpretations arrived at through inference. In Section 1 I present a brief overview of the ways in which default interpretations are approached in the current mainstream semantics and pragmatics. I include there both post-Gricean pragmatics and some more formal approaches to utterance meaning such as Segmented Discourse Representation Theory and Optimality-Theory Pragmatics. In Section 2, I discuss the question at what stage of utterance interpretation defaults arise. In brief, this amounts to the investigation as to whether, in addition to defaults that arise when the whole proposition has been processed, there 
are also 'local', pre-propositional defaults that arise on the basis of the processing of a smaller unit such as a word or a phrase. Section 3 follows with specifying the sources of default interpretation that give rise to two types of defaults: cognitive and social-cultural. In Section 4, I combine the results of the preceding two sections and suggest a more elaborate account of the compositionality of utterance meaning, incorporating the types of default interpretations. I also mention the direction in which this account could be developed. In the concluding remarks in Section 5 I point out the benefits of departing from the polarization of the 'default' - 'non-default' models, moving in the direction of the middle ground.

\section{Default interpretations in semantics and pragmatics: An overview}

\subsection{Default reasoning}

Bach (1984) advocates 'default reasoning' or 'jumping to conclusions' because we 'know when to think twice'. Default reasoning is an 'inference to the first unchallenged alternative'. It is defeasible, the hearer assumes that such a step in reasoning is compatible with what the speaker intended:

...default reasoning is reasoning that contains at least one defeasible step, and what that is can be described intuitively as follows. When you take such a step you do not think, 'Everything is OK, so I'll take this step'. Rather, you just take it unless you think something might not be OK.

Bach (1984: 40)

Bach's defaults are founded on the assumption that belief and intention come in various degrees of strength (see Bach 1987a, b). They have never been developed into a full theory of default interpretations, although Bach gave the general direction by emphasizing the role of standardization, going beyond the literal meaning which is facilitated by precedents of similar use of the particular expression. Standardization shortcircuits the inference process in that the hearer performs the inference without realizing it (see e.g. Bach 1995: 683; 1998: 713). ${ }^{1}$

\footnotetext{
${ }^{1}$ For an account of how such interpretations produce meanings that are implicit in what
} is said (implicitures) see Bach 1994 and a discussion in Horn 2006. 


\subsection{Presumptive meanings}

Levinson's $(1995,2000)$ default interpretations, called by him 'presumptive meanings', are generalized conversational implicata (GCIs) and do not reduce to semantics or pragmatics. They "sit midway, systematically influencing grammar and semantics on the one hand and speakermeaning on the other." (Levinson 2000: 25). His heuristics 'What isn't said, isn't' (Q-heuristic), 'What is expressed simply is stereotypically exemplified' (I-heuristic), and 'What's said in an abnormal way isn't normal' (M-heuristic), summarise the rational communicative behaviour that produces such default inferences. ${ }^{2}$ They explain the assumption that the hearer does not always have to go through the process of recovering the speaker's intentions but instead can take a 'shortcut', on the assumption that the interlocutors are co-operative. Default interpretations arise for various reasons, they come from various properties of thought and environment, and, according to Levinson, they come at various stages of the processing of the sentence. They are defeasible: they can be cancelled.

These features of presumptive meanings signal that while Levinson's account may neatly capture the generalizations about what is uttered and what is added by the addressee in the interpretation process and when, the psychology of utterance processing leaves a lot of scope for further theoretical and experimental research. The occurrence of local, word-based or phrase-based defaults is necessarily subject to frequent cancellation and cancellation is a costly process that should not be postulated freely. I return to this point in Section 2.

\subsection{Defaults and logics}

Defaults and nonmonotonic reasoning are also well acknowledged in logic and computational linguistics and can be traced back to the works of Humboldt, Jespersen and Cassirer, and more recently to Reiter's (1980) default logic and his default rules of the form:

$$
\frac{A: B}{C}
$$

meaning that $\mathrm{C}$ can be concluded if $\mathrm{A}$ has been concluded and $\mathrm{B}$ can be assumed (and not B cannot be proven, see Thomason 1997: 783). Default

\footnotetext{
${ }^{2}$ It has to be pointed out that, as Saul (2002) and Horn (2006) aptly observe, it is contentious whether Grice's original GCIs are default inferences in the first place: GCIs are speaker's meanings, while default meanings are the result of hearer's interpretation. See Horn 2006 for a discussion and some more pertinent references.
} 
reasoning is thus a type of reasoning which obeys laws of salience, common sense, and common-sense ideas of probability. Such defaults can be built into standard logic, they are not a pragmatic overlay over a semantic theory. ${ }^{3}$ One of the best-developed formal semantic theories that makes use of default rules of discourse is Segmented Discourse Representation Theory (SDRT, Asher and Lascarides, e.g. 2003). It contains a series of so-called rhetorical structure rules that 'glue' sentential logical forms together, specifying relations between them such as Narration or Explanation, according to the rule: if A, then (normally, defeasibly) B. Such relations are thus default relations, cancellable when information to the contrary is present.

\subsection{Constraints of Optimality-Theory (OT) Pragmatics}

In OT Pragmatics (e.g. Blutner 2000; Blutner and Zeevat 2004), pragmatic constraints account for the resulting interpretation. Since the meaning recovered from the syntactic structure underdetermines the expressed, intended proposition, a pragmatic mechanism of completion of this meaning has to be activated. OT Pragmatics proposes such a mechanism, conceived of as an optimization procedure, founded on the interaction of violable and ranked constraints. The selected, optimal proposition is the one that best satisfies the constraints. This selection is performed by the pragmatic system whose role is to interpret the semantic representation of a sentence in a given setting. This system is founded on the principles of rational communication worked out by Grice and subsequently by Horn $(1984)$ and Levinson $(1987,2000)$ in the form of the Q- and I/Rprinciples, introduced in Section 1.2. The I/R-principle compares different interpretations of an expression, while the Q-principle assesses the produced structure as compared with other unrealised possibilities: it blocks interpretations that would be more economically connected with those alternative, unrealised forms. Examples of interpretation constraints are STRENGTH (preference for informationally stronger readings), CONSISTENCY (preference for interpretations that do not conflict with the context), and FAITH-INT (faithful interpretation, interpreting all that the speaker said). FAITH-INT precedes CONSISTENCY which precedes STRENGTH in the ranking (see Zeevat 2000). Default interpretations are explained by the interaction of these constraints. For example, the fact

\footnotetext{
${ }^{3}$ The literature on the topic is vast See e.g. Thomason (1997) for an overview and e.g. Pelletier and Elio 2005; Benferhat et al. 2005, Veltman 1996. For defaults and the lexicon see e.g. Asher and Lascarides 1995; Lascarides and Copestake 1998.
} 
that we choose to bind an anaphor to a potential antecedent rather than make up an alternative antecedent (i.e. accommodate) can be explained in this way (see Zeevat 2004). The analysis relies on Smolensky's (e.g. 1986) concept of 'harmony maximization', according to which the output state is arrived at through the greatest possible consistency between constraints with respect to a given input. The rule of harmonic processing is then proposed on the sub-symbolic level as 'Go to the most harmonic available state' (Prince and Smolensky 2004: 20). ${ }^{4}$ Default interpretations of OT Pragmatics seem to be the closest to our ideal of default interpretations that genuinely occur in processing. In other words, they are not cancellable presumptive meanings: if the default interpretation has been arrived at, OT Pragmatics tells us how. If the default has been prevented from arising, the interaction of the constraints has to explain how it happened.

\subsection{Subdoxastic enrichment}

Recanati's (2002, 2003, 2004) solution to the enrichment of the meaning recovered from the syntactic processing of utterances includes saturation, that is completing a semantically incomplete proposition as in (3), as well as free enrichment: free in the sense of not being linguistically controlled and hence not pertaining to any unfilled slots in the logical form, as in (4).

(3a) The roof isn't strong enough.

(3b) The roof isn't strong enough to withstand the gales.

(4a) Everybody likes Paris.

(4b) Everybody I know likes Paris.

Recanati claims that such enrichment is automatic, it takes place subdoxastically, that is below the level of consciousness. Hearers are not aware of performing this enrichment and, unlike the derivation of implicatures, this process is not costly or effortful. It is not an inferential process. Such unreflective processes are dubbed primary pragmatic processes. They 'click into place' once the need for manipulating the output of grammatical processing becomes obvious to the addressee. Recanati's proposal of direct communication is founded on the model of perception. The pragmaticallyenriched, truth-conditional content of utterances is arrived at directly, just like perceptual content. Primary pragmatic processes are direct and

${ }^{4}$ I owe thanks to an anonymous referee for pointing out to me the importance of the concept of 'harmonic mind'. 
impenetrable, unlike the inferential processes that lead to implicatures. He calls this position 'anti-inferentialist' (Recanati 2002: 109). Unlike Levinson's, Recanati's defaults are processing defaults, they are not meanings that are presumed by the pragmaticist to ensue for a particular expression. They ensue in the particular situation of discourse.

The main point of contention in the current debate in the literature is the conscious-subconscious divide that differentiates this default enrichment of the linguistic meaning of the uttered sentence and the inferential generation of implicatures. It is unlikely that the dispute can be settled without empirical evidence one way or the other. The problem with designing appropriate experiments grows, therefore, to the central issue for furthering our understanding of what exactly is happening when hearers understand more than what the sentence literally says. I return to the issue of experimental evidence and types of defaults it eliminates and supports in Section 1.7.

\subsection{Default Semantics}

In Default Semantics (DS), the meaning of an utterance is a product of the merger of meaning information that comes from various sources: (i) word meaning and sentence structure, (ii) conscious pragmatic inference, and (iii) defaults (Jaszczolt, e.g. 2005, 2006). The latter are understood as salient interpretations that occur in a particular context of conversation. Like Recanati's subdoxastic meanings, these defaults cut across the generalized/particularized distinction in that they can arise either without, or with, the help of the situational setting. For example, (5a) is more likely to acquire a referential rather than an attributive interpretation, as in (5b):

(5a) The best novelist wrote Oscar and Lucinda.

(5b) Peter Carey wrote Oscar and Lucinda.

The salience and, on DS, the 'default status' of ( $5 b$ ) are dictated by the fact that the referential intention is stronger on that interpretation, or, more generally, by maximization of informational content. ${ }^{5}$

\footnotetext{
${ }^{5}$ I discussed extensively the intentionality of mental states that underlie speech acts in various publications and will not repeat the arguments here. See Jaszczolt, e.g 1997, 1998a, b, 1999a, b, 2000.
} 
Such default interpretations are shortcuts through the costly process of inference. Like Recanati's defaults, they are not products of conscious inference. However, it remains an open question as to whether their subdoxastic status warrants classifying them as qualitatively different components of meaning from those arrived at through conscious pragmatic inference. It seems more plausible to regard them as meanings that are so salient through being either (i) entrenched in our culture and society, or (ii) reflecting the characteristics of the human thought, that inference just ceases to be required. In other words, we can envisage a cline of inferential processes that has as one of its polar ends the scenarios in which such shortcuts occur. This question is taken up further in Section 4.

Further, the defaults of DS are, so to speak, more 'powerful' than those in other approaches. In DS, the role of the logical form as the output of syntactic processing is considerably reduced as compared with other post-Gricean accounts. There are situations in which the most salient meaning, dubbed 'what is said', will have little to do with the structure of the uttered sentence. Information from inference or from defaults can override information from the logical form. It has to be noted that the said/ implicated distinction is preserved: implicatures are simply propositions that are derived in addition to what is said. But note that both what is said and what is implicated can have little to do with the sentence meaning. I elaborate further on the theory itself in Section 4. For the moment, suffice it to say that defaults are classified there by their sources, they are also pragmatic through and through. They can make use of contextual and other background information and are not normally defeasible: they may simply not arise. Defeasibility cannot be precluded but it is very infrequent and ensues, for example, in garden-path processing. The way to think about this property is this. Defaults that draw on more specific information are more likely to hold than defaults that draw on less specific information. For example, the utterance 'Phoebe is a bird' will trigger the interpretation that Phoebe flies, but this can be overridden by further information that Phoebe is a penguin. If the piece of information that Phoebe is a penguin had been available from the start, the inference that Phoebe flies would not have arisen. In general, salient interpretations that draw on rich contextual background are less likely to be cancelled.

\subsection{Features and types of defaults}

It is evident from this brief overview that there is considerable support in various semantic and pragmatic theories for the existence of default 
interpretations. But it is also clear that there is no consensus as to what default interpretations are. To sum up, we have found differences on the following fronts, summarized as D1-D5:

D1 Defaults can belong to competence or performance.

D2 Defaults can be defeasible when there is little contextual background, butare not normally defeasible when they can draw on substantial contextual or other background information. ${ }^{6}$

D3 Defaults can, but need not, be 'automatic': they can amount to unconscious (subdoxastic) enrichment of the output of the syntactic processing of the uttered sentence.

D4 Defaults are uniform or come from qualitatively different sources in utterance processing.

D5 Defaults enrich the logical form (the underdetermined semantic representation of the sentence) or they can also override it.

Other differences to be investigated in the following sections are D6 and D7:

D6 Defaults necessarily arise quicker than inference-based interpretations and hence can be tested for experimentally by measuring processing time.

D7 Defaults are always based on the proposition or can be 'local', sub-propositional, based on a word or a phrase.

Naturally, these properties are interrelated and some go together better than others. For example, Levinson's defaults are defeasible, sub-propositional, competence-based and hence also arise faster than inference-based meanings. The 'competence-based' characteristic requires more explanation here. Since Levinson's presumptive meanings arise irrespective of context, are automatic and defeasible, they can be easily classified as competence defaults on a par with the rhetorical rules of Asher and Lascarides (2003), rather than as performance defaults. For example, scalar implicature such as (6b) arising out of the scale <all, some> is a clear example of a competence default: the property of the quantifying expression 'some' triggers the strengthened reading.

(6a) Some laptops are reliable.

(6b) Some but not all laptops are reliable.

\footnotetext{
${ }^{6}$ In other words, they are progressively less defeasible with the increase of background information.
} 
Inference to a stereotype such as that in (7b) is triggered by an indefinite description and not by the context of utterance.

(7a) I talked to a man who advised me to try Polish ski resorts.

(7b) I talked to a man (who was not my close relative or friend) who advised me to try Polish ski resorts.

Such defaults are said to arise due to the semantic properties of expressions and they are automatic: the processing agent does not consult the available context before he or she accepts them, but instead takes them for granted and, if necessary, cancels them later on. According to Levinson, these defaults arise as soon as the triggering word ('some') or phrase ('a man') is encountered. ${ }^{7}$

\subsection{Features of defaults and experimental testing}

We now move to the feature D6 and the experimental testing of the status of conflicting interpretations. This cluster of properties, namely defeasibility, locality, and foundation in competence is relatively easy to test. Predictably, current experimental pragmatic literature is successful in testing this particular type of default. It suffices to check, in carefully controlled conditions, whether the default meaning takes shorter to produce than the non-default one. ${ }^{8}$ One can also test for the sensitivity to default meanings displayed by subjects of different ages, to produce an argument from language development (Noveck 2001; Papafragou and Musolino 2003; Musolino 2004). By demonstrating that such interpretations are not faster to achieve and are not displayed in the behaviour of five-year olds, we can obtain a strong argument against their existence in processing. ${ }^{9}$ On the other hand, performance-based, rarely

\footnotetext{
${ }^{7}$ What is required at this point is a cognitive explanation of the property 'automatic'. It seems that an explanation on a sub-symbolic level making use of Smolensky's (1986) 'harmony maximization' can be applied here. See Section 1.4 and fn 4.

${ }^{8}$ See articles in Noveck and Sperber 2004.

${ }^{9}$ The argument from language development is particularly applicable to Levinson's presumptive meanings because this is the most radical, so to speak, type of default. When the child judges that the sentence with a weaker meaning is a correct description of a situation in which the stronger version would be applicable, such as (i.a) and (i.b) respectively, then the automatic, time-free, inference-free, competence-based, highly defeasible defaults have to appear dubious. See Papafragou and Musolino 2003.

(i.a) Some of the horses jumped over the fence.

(i.b) All of the horses jumped over the fence.
} 
cancellable salient meanings that can draw on contextual information are much more likely to prove correct in neurolinguistic research, the more so that they are all but theoretical elaborations of common intuitions of default senses.

In a nutshell, the state of the art in experimental pragmatics is as follows. Noveck $(2001,2004)$ investigated the acquisition of modal and quantificational constructions and his most interesting finding was that when presented with a sentence such as (8a), only 41 per cent of adult subjects regarded it is true, while 85 per cent of children were happy with it. Most adults understand (8a) as (8b) and judge it to be false. In other words, their understanding of 'some' is 'some but not all'.

(8a) Some elephants have trunks.

(8b) Some but not all elephants have trunks.

Now, as Noveck says,

These developmental findings do not favour one account over another because both could explain it. From the Default perspective, it could be claimed that scalar inferences become automatic with age and that our results are simply revealing how such inference-making matures. In contrast, Relevance Theory would suggest that children and adults use the same comprehension mechanisms but that greater cognitive resources are available for adults, which in turn encourages them to draw out more pragmatic inferences.

Noveck (2004: 307)

But when the task complexity was increased, it appeared that the logical interpretation arose faster, at least for children. Children were presented with descriptions of situations in which the order of narration inverted the sequence of events and were asked for their judgement on the truth or falsity of the description of what happened. The reaction time was measured, that is the time before the answer 'yes' or 'no' was produced, and it was found that the children who accepted the inverted order as a true description did it faster, while those responding 'no' took on average two seconds longer. ${ }^{10}$ The obvious conclusion is that the logical interpretation of 'and' takes time to become enriched to temporal 'and', at least for children.

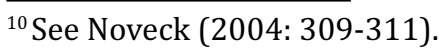


The experimental design assumes here Levinson's notion of automatic, cancellable defaults and rests on the assumption that testing the relative time it takes to produce a default meaning as opposed to the inferentially derived meaning is going to provide a compelling argument for or against defaults:

...if Logical responses are made more quickly than Pragmatic responses, we have evidence against a default system of inference.

Noveck (2004: 314)

and

If one could provide evidence showing that pragmatic interpretations of scalars are the first to arise and that interpretations that require their cancellation occur subsequently, then the default inference view would be supported. However, if one could show that minimal interpretations are at the root of initial interpretations and that pragmatic interpretations arise only later, that would be further support for Relevance Theory.

Noveck (2004: 311)

Noveck discusses at length cancellation of defaults that requires extra processing time. Bezuidenhout and Morris (2004), again, found their experiments on the time argument and monitor the movement of the readers' right eyes to show whether there is cancellation of a default 'some but not all' when 'in fact all' is encountered. This clearly shows that the notion of default accepted in current experimental studies is rather specific and restricted. Pace Noveck, Bezuidenhout and other experimenters, there is no 'the default view' or 'Default Model' of pragmatic processing: there are many different models, each with its own strengths and weaknesses, and each using a different combination of values summarized in Section 1.7 as D1-D7. The results of the extant experiments should thus be qualified as pertaining to one, or to some subset, of the family of views that use the term 'default interpretation'.

\section{Pre-propositional and post-propositional defaults}

Let us now move to the discussion of D7 and the point in utterance interpretation at which defaults arise. We have established, among others, that when 'typical', 'normal' readings are regarded as salient in a common- 
sense, pre-theoretical way, they raise little objection: they seem to be a fact of discourse. The controversy begins when the defining properties of such readings are under scrutiny, such as their inferential or noninferential status, cancellability, or the stage in utterance processing at which they are produced. In this section I concentrate on the controversy surrounding the unit of utterance that gives rise to such defaults.

According to Levinson $(1995,2000)$, default, preferred interpretations, or presumptive meanings, arise out of the structure of the utterance. They can arise even before the processing of the utterance is completed, i.e., even before the intended proposition has been processed: they arise locally, pre-propositionally. This is so because discourse interpretation proceeds, so to speak, bit by bit, incrementally, and there is a stage at which the part that triggers a default interpretation has been uttered, the default has been produced, while the processing of the utterance has not yet been completed. For example, on such a pre-propositional account, 'some of her lectures' in (9) triggers the 'some but not all of her lectures' interpretation as soon as the quantifying expression 'some' has been processed. I shall mark the default meaning by $(\rightarrow d$...) and write it in the place in the utterance in which it allegedly occurs in processing.

(9) Some ( $\rightarrow$ d some but not all) of her lectures are inspiring.

Such default meanings are said to be quite common in language and occur in a variety of constructions. Let us have a look at (10) and (11).

(10) The coffee spoon ( $\rightarrow$ d spoon used for stirring coffee) is dirty.

(11) I bought him a silver spoon $(\rightarrow \mathrm{d}$ spoon made of silver) as a christening present.

The inference in (9) is due to the Q-heuristic ${ }^{11}$, while examples (10) and (11) conform to the I-heuristic. These three heuristics, however, are merely convenient generalizations. Moreover, they are not even of the same epistemological status. While I-implicatures such as those in (10) and (11) arise as inferences to a stereotype, Q- and M-implicatures are more complicated in that they arise due to a comparison with what might have been, but was not, uttered. This demonstrates that default meanings arrived at through different heuristics have a different status. Let us look at examples (10)-(11) again. It is evident that not all of them give rise to equally obvious

${ }^{11}$ See Section 1.2. These heuristics originated in Levinson 1987. Grice's original maxims have also been reworked in a similar way by Horn, see e.g. 1984, 1988. For an introduction see Jaszczolt 2002, Chapter 10. 
and uncontroversial default interpretations. Examples (10) and (11) are, arguably, the best candidates for defaults. On the contrary, (9) is more likely to be compatible with 'some and possibly all', than 'coffee spoon' is with, say, 'spoon used for scooping coffee beans' or 'silver spoon' with 'spoon used for stirring liquid silver'. However, 'silver spoon' and 'coffee spoon' have a strong sense of lexical compounds about them and hence it can be argued that what we consider to be default meaning is in fact a lexical meaning. This should not be surprising as generalized implicatures are generally believed to be a source of semantic change (see e.g. Traugott 1999; Traugott and Dasher 2002). ${ }^{12}$ But using the special case of 'near-compounds' to argue in favour of pre-propositional defaults in general ceases to be plausible if they are indeed compounds with lexical meaning given by their respective $(\rightarrow \mathrm{d}) \mathrm{s}$. Now, sentence (9) does indeed normally trigger an interpretation 'some but not all'. But this is likely to be caused by the specification of the domain of quantification by means of the preposition 'of', or by a tacit assumption that 'some' normally comes with such a domain. Hence, although the meaning 'not all' is likely to arise, this is not a clear case of a lexical default. ${ }^{13}$

It seems that in order to constitute a comprehensive account, pre-propositional defaults will have to subsume a special case of default interpretation that takes place after the whole utterance has been produced. For example, in (12a), the adjective 'warm' occurs at the end of the utterance.

(12a) Coffee is warm $(\rightarrow \mathrm{d}$ not hot).

This is not surprising: 'warm' in (12a) just happens to occur at the end of the sentence, there is otherwise nothing special to it. To be consistent, we have to regard this as a special case of a pre-propositional default that can be contrasted with the original, Gricean, 'post-propositional' scenario that would look as in (12b):

(12b) Coffee is warm. ( $\rightarrow$ d Coffee is not hot).

In (12b), the hearer recovers the proposition first and then ascribes to it the salient interpretation: the coffee is only warm, not hot.

${ }^{12}$ According to this view, pragmatic meaning is conventionalized and reanalyzed as semantic meaning. Or, according to the well quoted slogan, inferences become references' (Traugott and Dasher 2002: 35, after Bolinger).

${ }^{13}$ It has to be pointed out that by 'domain specification' I do not mean what is discussed in the literature as 'domain restriction'. All I mean is that it is plausible to assume that the lexical item 'some' comes with the salient meaning 'some out of a certain domain'. I owe thanks to an anonymous referee for suggesting I clarify this point. 
The main advantage of introducing such pre-propositional defaults is that they eliminate the need to postulate a level of utterance interpretation on which we have a proposition without such a default inference. We obtain a more economical picture of utterance interpretation on which we have only one proposition: the one that pertains to the default interpretation or to a non-default one triggered by a contextdriven overriding of what is normally presumed. So far so good, but are Levinson's presumed meanings truly context-free? Let us take (13a). 'A man' is interpreted as 'not the speaker's husband, brother, father, friend, or any other close relation or acquaintance' as in (13b):

(13a) I saw a man driving an old Bentley.

(13b) I saw a man $(\rightarrow$ d not the speaker's husband, brother, father, friend, or any other close relation or acquaintance) driving an old Bentley.

Let us now compare it with (14) where, if I am correct, no such 'default inference' takes place. ${ }^{14}$

(14) There is a man in the Women's League. He is a treasurer and a good friend of mine.

Intuitively, in (14), 'a man' does not seem to give rise to a pre-propositional default to the effect 'not the speaker's husband, father, brother, or any other close acquaintance or relation'. In fact, neither does it seem to give rise to a post-propositional default: it seems to be a safe stipulation that the processing of an utterance of the first sentence in (14) ('There is a man in the Women's League') does not result in such an enriched reading by default. In the absence of empirical evidence this claim has the status of an intuitively plausible hypothesis. However, even 'experimenting' with the possible intonation patterns for this sentence corroborates this stance. All of (14a)-(14d) are equally conducive to the continuation by the second sentence of (14) ('He is a treasurer and a good friend of mine.').

(14a) There is a MAN in the Women's League.

(14b) There is a man in the WOMEN'S LEAGUE.

(14c) There IS a man in the Women's League.

(14d) There is a man in the Women's League.

(uttered with an intonation pattern of an ordinary assertion)

${ }^{14}$ Cf. the discussion of example (7) in Section 1.7. 
In short, we have the following difficulty. Levinson's defaults are automatic, they are generated when the trigger for a relevant default has been uttered and hence can be generated locally. When they do arise locally, they can be cancelled later on as discourse progresses. At the same time, intuitively, they seem to be generated unless the context prevents them from arising. Let us take a simple example of number terms as in sentence (15).

(15) Fifty-five votes in favour are needed to ratify the amendment.

Assuming for the purpose of this argument that the semantics of number terms is either 'at least $n$ ' or is underdetermined, there are two possible scenarios here. 'Fifty-five' can trigger, locally, an interpretation 'exactly fiftyfive', to be cancelled subsequently when the content of the sentence makes it obvious that the intended meaning is 'at least fifty-five'. Or, in view of the topic of the conversation prior to sentence (15), the 'exactly' default does not arise and the 'at least' meaning is produced instead. Similarly, in (16), the definite description 'the first child' may give rise to a default, referential reading that is cancelled as soon as the qualifier 'to be born in 2066' is processed, or alternatively one can argue that the whole noun phrase is to be regarded as a unit and the default referential reading does not arise because the future-time reference of the event is obvious from it.

(16) The first child to be born in 2066 will be called William.

Any further discussion of this dilemma would be futile in the current state of theorizing and experimenting: we simply don't know what is happening there. We can conclude that if defaults can be so very local as to arise out of a morpheme, word, or part of a phrase, they are part and parcel of the computational power of grammar and they are likely to belong to the lexicon, syntax, and epiphenomenally to semantics. If this theory proves to be correct, then their high defeasibility is a natural outcome and is not to be shunned. ${ }^{15}$ But there can be no reliable answer to the questions of locality and cancellability until there is compelling empirical evidence one way or the other.

For the time being, we have to remember that cancellation is a costly move and it must not be postulated unless there is evidence

\footnotetext{
${ }^{15}$ This view is held by, among others, Chierchia (2004) and Landman (2000). Chierchia demonstrates that scalar implicatures fail to arise in downward-entailing contexts, that is contexts that license inference from sets to their subsets (e.g. where 'any' is licensed). This shows that there is a reliable syntactic explanation of their behaviour. See Chierchia et al. 2004. See also Recanati 2003 for a critical overview.
} 
in its support. So, perhaps, for the time being, it is more effective from the methodological point of view to maintain the old-fashioned Gricean picture of defaults that are added somehow or other to the total output of grammatical and lexical processing. This is the path I will pursue in Section 4, using the framework of Default Semantics.

To conclude the discussion so far, not only are local, prepropositional defaults not sufficiently supported to be taken for granted, but also there are different degrees to which salient meanings are really salient. ${ }^{16}$ As we have seen, the process of formation of such salient readings is a subject of debate in that it can be conceived as inference, as noninferential, 'instantaneous', so to speak, default, or even as a more theoryladen category of 'subconscious inference. ${ }^{17}$ I discuss this issue further in Section 3.1. At the moment, and with reference to examples (13) and (14), it suffices to observe the following dependencies:

If

(i) default interpretations are conceived of as pre-propositional and

(ii) they are the result of an interpretation of an expression in $a$ particular utterance,

then it seems that

(iii) the utterance constitutes a context for the interpretation of this expression.

We end up with a rather problematic concept:

(iv) Local default interpretations are defaults for that context.

${ }_{16}$ Pre-propositional defaults have also been discussed in Recanati 2003 who demonstrates that they fall within the scope of operators such as disjunction or implication:

(i) Bill and Jane have three or four $(\rightarrow$ d exactly three or exactly four) children.

(ii) Every father feels happy if his daughter gets married and gives birth to a child ('and' $\rightarrow d$ and then); much less if she gives birth to a child and gets married ('and' $\rightarrow d$ and then).

adapted from Recanati (2003: 2).

In (i), 'three' and 'four' are given the 'exactly' reading that is not derived from the 'at least three or at least four', as the global enrichment account would predict. In (ii), the two cases of temporal enrichment of the conjunctions are internal to their clauses: the antecedent and the consequent respectively.

${ }^{17}$ See Section 1 above and Recanati 2002, 2004. 
This is supported by the observation that 'a man' intuitively triggers the interpretation 'a man who is not the speaker's relative or acquaintance' in some contexts but not in others. The question arises as to whether salient meaning so conceived warrants the name of a default interpretation. It seems that it does. Context is understood here narrowly, as the current utterance, and hence the provisional term 'default interpretation' is justified in order to distinguish this type of meaning from a full-blown, context-dependent interpretation which is the result of a full-blown, incontestable pragmatic inference. To repeat, the question as to whether this interpretation is arrived at automatically and explicable through, for example, Smolensky's maximization of harmony on the sub-symbolic level, ${ }^{18}$ or through a process of (conscious or subconscious) inference, is still a contentious issue, as the overview in Section 1 demonstrates.

To sum up, we are left with a set of unresolved differences in the defining set of characteristics of defaults. It is evident that the question of what default interpretations are is still an open one - the more so that the cases under scrutiny tend to require contextual or other background knowledge triggers. Surely, there are some syntax-triggered and semanticstriggered defaults such as those for anaphora (and presupposition) resolution, reference assignment, unpacking of ellipsis, and they are all governed by syntactic or semantic principles of some sort. ${ }^{19}$ Next, there are various shortcuts through inference. But if the criterion for defaults were to be that default meanings arise prior to any processing of the context and without any processing of the speaker's intentions, then we do not have a uniform category that can fulfill it.

\section{Towards a typology of default interpretations}

As can be seen from this sample of views on defaults, there is no consensus as to the meaning of the term. Nevertheless, the following generalizations (G1-G2) can be made:

G1 Defaults are governed by principles of rational communicative behaviour such as neo-Gricean heuristics, logic of information structuring, or some other defeasible logic.

G2 Defaults are salient meanings arrived at with the help of information that comes from outside the meaning of words and the structure of the sentence.

\footnotetext{
${ }^{18}$ See Section 1.7

${ }^{19}$ I discuss them in Chapters 4 and 7 of Jaszczolt 2005.
} 
But it will not suffice to postulate and attempt to support the view that utterance interpretation makes use of more or less salient meanings. If we tried to stop at this point, we would once again end up with an eclectic notion of default, which is against a methodological requirement of reliable definitional characteristics of category membership. We know that defaults are shortcuts through inference, but this is about all that unifies them as a category.

Further divisions stem out of the provenance of defaults. I suggested in the previous sections that defaults come from various sources such as the properties of language, the way the mind works, the way societies are organized, the cultural heritage of the interlocutors, and other background material. These sources of defaults are not necessarily mutually exclusive. While the reliable ontology of defaults may be beyond our reach at present, we can attempt their classification on epistemological grounds by attending to these different ways in which we understand more than the sentence alone contains. As a step towards this classification, I discuss below four main sources of such salient embellishments of sentence meaning, beginning with 'the way we think': the properties of mental states. It has to be stressed, however, that in the current state of research on the salience of interpretations any attempted classifications must be regarded as, at best, viable hypotheses that will provide food for empirical testing.

\subsection{Cognitive defaults}

Believing, fearing, doubting, knowing, are all examples of mental states. These states can be externalized, conveyed to another person, by means of language. The mental states that will be of interest to us are those that have content, or are about something. For example, to believe or to doubt is to believe something and doubt something. This property of some mental states is called their intentionality. Intentionality has been the subject of philosophical disputes at least since Aristotle, and through medieval philosophy, nineteenth-century phenomenology, to the speech act theory of John Searle. We shall therefore take the importance of his property for granted and move on to how it can be useful for understanding some default meanings. Suffice it to say that we shall assume that propositions are built up by composing meaning out of elements which have intentionality. This intentionality of units of language has to be understood as intentionality of the brain, the mind, and the mental state, and only derivatively, 
epiphenomenally, of language. The argument goes that if mental states are intentional, then so are their externalizations in the form of sentences about these mental states (beliefs, doubts, fears, and the like). ${ }^{20}$

Intentionality becomes useful when we try to explain the reason behind the salience of, say, referential interpretations of definite descriptions such as 'the author of Oscar and Lucinda' in (17). It is intuitively plausible that the addressee B is likely to react to A's statement by posing a question that assumes that $\mathrm{A}$ knows who the author of this novel is.

(17) A: The author of Oscar and Lucinda is a very good writer. B: Really? Who is it?

B's reaction is compatible with the strongest intentionality, pertaining to the referential reading of the description. The strongest intentionality is the default intentionality and it corresponds to the referential, correct reading of the description where it stands for Peter Carey. Due to the presence of a cognitive, phenomenological explanation, I shall call such readings cognitive defaults. However, we can discuss such defaults on two levels of explanation: by invoking intentionality, or we can remain on the level of language and explain them with reference to degrees of speaker's intentions. Needless to say, the first option is more reliable in that intentionality as a property of brains and minds is, alas, more reliable an explanans than speculations about speaker's intentions. Cognitive defaults pertain to ample types of language constructions and phenomena. They explain the use of temporal expressions, the construction of anaphoric dependencies, and the use of number terms. ${ }^{21}$

\subsection{Physical defaults?}

In some cases, the default interpretation ensues because the addressee tacitly knows what the scenario that corresponds to the utterance would be. For example, in (18) and (19), it is obvious to the addressee that water has to be fully immersed in the vase, while flowers have stems inside the

\footnotetext{
${ }^{20}$ Language is intentional insofar as it allows for representing beliefs, doubts, fears, and other mental states. See Lyons (1995:44). For Fodor (1994), 'intentional' is synonymous with 'representational', having informational content. In brain science, one talks about brain cells being intentional in virtue of being about things other than themselves. See Damasio (1999: 78-9) and Jaszczolt (2005: 49).

${ }^{21}$ All of these are discussed in detail in Jaszczolt 2005.
} 
vase and decorative heads above. This tacit knowledge is independent of any context of conversation.

(18) There is water in the vase.

(19) There are pink flowers in the vase.

There are ample possible explanations of this tacit knowledge. There is a physicalist explanation to the effect that liquids have to be fully enclosed in a vessel while solids need not, a functionalist explanation to the effect that water is for keeping flowers alive while flowers are to be visible to be aesthetically pleasing, and a cognitivist explanation that humans normally experience scenarios of these types where 'in' is used as in the above examples. Undoubtedly there are more hypothetical explanations to be produced but this issue is tangential to our purpose.

The question arises as to whether salient interpretations such as those in (18) and (19) constitute a separate type of default and, if so, what are its defining characteristics. This default arises because of what the world is like and/or because of what we perceive it to be like. The natural name for it would be a physical default. However, it is at least disputable whether we need the concept of a default interpretation to account for the processing of 'in'. In spite of the post-Gricean tradition of subsuming spatial expressions under default pragmatic enrichments (e.g. Levinson 2000), there is little reason to do so. For example, in (18) and (19), the two senses of 'in' are not very different from each other. The differences are not very salient either. Moreover, in the case of other spatial expressions, where the meanings differ, the differences can be ascribed to the context, as in (20) that allows for two readings of 'under': floating within the boundaries of the bridge, or moving towards the bridge. ${ }^{22}$

(20) The bottle floated under the bridge.

If I am correct, then the interpretations of spatial prepositions depend on the objects they relate. For example, we know that water is in $(\rightarrow \mathrm{d}$ inside) the vase because we know enough about liquids to envisage this. We know that, say, boats tend to move forward and hence they would normally float under ( $\rightarrow \mathrm{d}$ in the direction of) the bridge, albeit this can be easily overridden in the context. We also know that, say, buoys normally float in place, and hence they float under $(\rightarrow \mathrm{d}$ within the boundaries of $)$ the

${ }^{22}$ The literature on spatial prepositions is vast, both in cognitive linguistics (e.g. Talmy 1985, 2000; Jackendoff 1990, 1991) and typology (Levinson 2003). 
bridge. ${ }^{23}$ Since, as it seems to me, we have no preconceptions about floating bottles, then context has to step in to help with the inference in (20). All in all, there is little evidence of physical defaults. The salient interpretations, where there are such, in the case of spatial prepositions can possibly be subsumed under a broader category of, say, cultural defaults in that it is culture in which we are immersed that gives speakers access to such default meanings. I move on to cultural defaults in the following section.

\subsection{Social-cultural defaults}

It is not difficult to produce examples of salient interpretations that arise due to some cultural or social stereotypes or cultural or social knowledge. In (21a), it is the shared cultural knowledge that almost invariably produces the interpretation (21b) in most (reasonably educated) speakers within the western culture.

(21a) Pablo's painting is of a crying woman.

(21b) The painting by Pablo Picasso is of a crying woman.

Cultural knowledge allows the addressee to identify Pablo as Pablo Picasso, and the possessive as authorship rather than, say, ownership. Similarly, in (22b), the salient interpretation arises due to the shared knowledge that babies are normally raised by their own parents.

(22a) The baby cried and the father rocked the cradle.

(22b) The baby cried and the baby's father rocked the cradle.

Again, as before, I shall tentatively assume that the readings in (21b) and $(22 \mathrm{~b})$ are non-inferential. The assumption is founded on the methodological principle of economy adopted here, stating that if there are alternative explanations, the more economical one is selected. In other words, since there is no compelling evidence that we should assume the existence of conscious processing, such processing will not be assumed. The interpretation is automatic, instantaneous and unreflective. ${ }^{24}$ Similarly, the readings 'secretary' $\rightarrow d$ 'female secretary', or 'nanny' $\rightarrow d$ 'female nanny', discussed in Section 2, are unlikely to be the result of conscious inference. Instead, the tacit social knowledge produces, unreflectively, the

\footnotetext{
${ }^{23}$ Alternatively, one can assume that 'float' is ambiguous between an activity and accomplishment verb.

${ }^{24}$ Ironically, these defaults are called by Levinson (2000) 'inferences to a stereotype'!
} 
senses enriched to these defaults. But note that, as I discussed in Section 2 , these defaults can be stronger or weaker. There may be a cut-off point at which salient interpretations are not so salient as to justify calling them 'defaults'. When I proposed a cline of inferential processes in Section 1.6, I also remarked that defaults are a matter of degree. This claim can be used now for discussing the properties of social-cultural defaults. The word 'nanny' can trigger an unreflective enrichment to 'female nanny'. However, the word 'nanny' may activate various other salient properties of typical nannies derived from such cultural icons as Mary Poppins, Jane Eyre, or Fräulein Maria from The Sound of Music, such as 'young', 'pretty', 'musical', 'strict' or 'lovable'. There is a cut-off point, which is as yet to be experimentally established, beyond which such embellishments do not warrant the label of default interpretations.

It has to be pointed out that, while cognitive defaults are well motivated by their property of strong, undispersed intentionality, socialcultural defaults have no such characteristic property to recommend them. They are only motivated by the methodological requirement not to postulate inferential processes beyond necessity. They are hardly distinguishable from cases of conscious pragmatic inference, they are simply on the polar end of an 'inference +salience' cline. As I observed before in Jaszczolt (2005: 56),

The boundary between such social-cultural defaults and social-cultural inferences can only be assumed as methodologically desirable and psychologically plausible. But any classification of interpretations as social-cultural defaults or conscious inferences based on social or cultural knowledge is still largely a matter of speculation.

One cannot discard them, though. Culturally and socially salient meanings are a fact of conversation. They may contribute to the truth-conditional meaning of the utterance - on the post-Gricean construal of truthconditional semantics such as the approach discussed in Section 4.

\subsection{Lexical defaults?}

In the neo-Gricean literature, the behaviour of sentential connectives such as and, or, if, not is said to be subject to default inferences (see e.g. Levinson $1995,2000)$. Let us first look at negation in negative-raising. Negativeraising is a tendency for the main-clause negation to be understood as the 
subordinate-clause negation, as in (23a) that is normally interpreted as (23b).

(23a) I don't think Shrek is funny.

(23b) I think Shrek is not funny.

This shift of the scope of negation works well with the verb 'to think' but does not extend to all verbs of propositional attitude. For example, (24a) does not communicate (24b) but instead seems to communicate the opposite attitude, something to the effect of (24c).

(24a) I don't hope England will win.

(24b) I hope England will not win.

(24c) I wish against hope that England will win.

Is negative-raising a case of a default interpretation? Since the phenomenon is restricted to only some verbs, it probably is not. We can perhaps consider it to be a default for these verbs and subsume it under cognitive defaults on the understanding that the informativeness of (23b) is greater than that of (23a) taken literally. In (23b), an attitude to a comment about a certain film character is expressed, whereas the literal meaning of (23a) is merely that the speaker has no mental state concerning the amusement value of the famous ogre. But this explanation is rather far-fetched in that we are not comparing here members of a gradable category: a thought about a property of Shrek is not directly comparable to the total lack of a thought on the matter. All in all, it seems that negative-raising is not a good candidate for a word-based (lexical) default.

Implication has also been regarded as a trigger for presumptive meanings through its frequent 'perfection' to an equivalence, as in (25b):

(25a) If you know the password, you can log in.

(25b) If and only if you know the password can you log in.

Levinson $(1995,2000)$ accounts for this perfection by means of the I-heuristic. In our proposed classification, we could try subsuming ifstrengthening under cognitive defaults and argue that intentionality is stronger in (25b) and that (25b) is more informative. This, however, is overstretching the tool of intentionality. By pragmatically perfecting the conditional we are adding fine detail to the meaning of (25a), that is, we are increasing the granularity of the description of the situation. A similar argument can be constructed for conjunction. (26b) communicates more 
K. M. Jaszczolt: Varieties of Defaults

information than the linguistic meaning ${ }^{25}$ of $(26 a)$ rather than a sense that is comparable to another, less salient, sense.

(26a) Lidia hurt her finger and couldn't play the violin.

(26b) Lidia hurt her finger and as a result couldn't play the violin.

Default interpretations have also affected the analysis of the semantic properties of number terms. A number term $n$ has been claimed to have the 'at least $n$ ' semantics, the 'exactly $n$ ' (punctual) semantics, or the semantics that is ambiguous/underdetermined between 'at least', 'at most', and 'exactly'. ${ }^{26}$ If we follow the underdeterminacy path and the argument from the strength of intentionality and intention, then the 'exactly' interpretation appears the default. In arguing for the punctual, 'exactly' semantics, Koenig (1993: 147) also makes use of the relative informativeness of interpretations: greater informativeness is the norm, and greater informativeness is associated with the property of being a proper subset of a truth set, that is including a smaller set of scenarios compatible with, say, (27).

(27) Mary has four brothers.

The interpretation on which Mary has neither fewer nor more than four brothers wins over the one on which she has four and perhaps even five or six. Now, assuming for the moment that the underdetermined semantics is the correct view, we could easily apply the argument from the strength of intentionality and intentions again: the output of syntactic processing leaves utterance meaning underdetermined, and then the strength of intentionality dictates in which direction the enrichment proceeds. The strongest aboutness pertains to the proper subset of a truth set, that is to the reading on which more information is conveyed and the set of scenarios is most restricted ('exactly four', no more and no less). However, once again, we have to beware of overstretching the class of cognitive defaults to cases where it may not be necessary. Experimental evidence and argumentation both suggest the following alternatives: either (i) the semantics of number terms is punctual ('four' means 'exactly four'), or (ii) the semantics of number terms is underspecified, but the 'exactly' interpretation is the normal, default one (see Musolino 2004). Hence, at the moment, we have to resort to theoretical arguments. Naturally, one can

${ }^{25}$ For a detailed bibliography and for my detailed analysis of default properties of sentential connectives see Jaszczolt 2005, Chapter 8.

${ }^{26}$ For a selection of views see Horn 1984, 1992; Levinson 2000; Carston 1998b; Koenig 1993; Geurts 1998; and Bultinck 2005. 
continue (27) by cancelling this 'exactly' sense as in (28), but this move is not qualitatively different from, say, the correction in (29).

(28) Mary has four brothers. In fact, she has five but the fifth one is only her half-brother.

(29) I have been to China. Well, strictly speaking, I have been to Taiwan.

We would not want to say that 'four or more' or 'China including Taiwan' are alternatives to the salient readings: 'exactly four' and 'People's Republic of China'. And if they are not, there is no need for defaults there. All in all, there is no evidence for the need of a word-based category of default.

\section{Future directions}

This is where my current vivisection of defaults ends: 'default' ends up as a label for widely understood salient interpretations. What follows in this part is a taste of what is next to be done, namely the incorporation of defaults so-conceived into a fully fledged, compositional theory of discourse meaning. I will stop at setting some desiderata and signalling the direction in which such a theory may develop.

Firstly, we have to address the question of how various sources of default meanings interact with other sources of meaning information. In other words, it may be more promising to start with the question of whether utterance meaning that is arrived at through grammatical processing and enrichment (including default enrichment) is amenable to an analysis in terms of a truth-conditional theory of meaning, be it semantic or pragmatic. We have two options here. One is the by now standard route of underdetermined logical form, enriched by pragmatic inference and, on some accounts, also through default enrichment, that results in truth-conditional semantic representations - representations that allow for the intrusion of pragmatic input. ${ }^{27} \mathrm{~A}$ variation on this view is Recanati's (2004) truth-conditional pragmatics, where free, top-down pragmatic enrichment operates on logical forms. 'Free' and 'top-down' stand there for embellishments that are not linguistically controlled; that is, they do not have any triggers in the logical form. The other option is

27 This topic has been particularly amply discussed in the literature. For seminal works, see Carston 1988 and Recanati 1989. See also Carston 2001, 2002a, b; Recanati 2004. For reviews of various approaches from different perspectives, see Recanati 2005; Cappelen and Lepore 2005; and Jaszczolt 2002. 
put forward in Default Semantics (Jaszczolt 2005). Instead of seeing the output of pragmatic inference and of defaults as 'intrusions' into some already entrenched unit, namely logical form, all the sources of meaning information are treated on a par: the sentence's logical form, default senses, and the output of pragmatic inference all provide chunks of meaning information that merge to produce the representation of utterance meaning. In this section I consider the latter option in more detail.

Cognitive and social-cultural defaults fit very well with Recanati's $(2003,2004)$ free enrichment within his truth-conditional pragmatics. But, since at least some of these salient meanings are automatic and unreflective, relegating them to the ancillary role of a finishing touch on the logical form does not seem quite correct. It would imply that the logical form is processed first, while the enrichment is always temporally second. What we want instead is an arrangement in which default interpretations and (conscious) pragmatic inference are treated on an equal footing with the processing of grammar and lexicon. Using the framework of Default Semantics, we can identify the following sources of information about utterance meaning: word meaning and the structure of the sentence uttered (WS), (conscious) pragmatic inference (CPI) ${ }^{28}$, as well as two types of 'shortcuts' through this inference, discussed in the preceding sections: salient interpretations of the social-cultural and cognitive type (SCD and CD). Jointly, these sources give as output a representation of utterance meaning called 'merger representation'. This representation can be broadly compared to Recanati's notion of 'what is said' or the relevancetheoretic 'explicature' in that it is a representation of the speaker's thought as recovered by the addressee in the process of communication. It is supplemented by implicatures, understood as additional thoughts, derived by means of the sources SCD and CPI. The main difference between the merger representation and the explicature is that the first is much less restricted by the syntactic processing of the sentence: the output of WS can be overridden by the output of any other source. ${ }^{29}$ So, if the most salient intended meaning happens to be what would on relevance-theoretic or Recanati's accounts be called an implicature, this implicature is the main communicated thought and is therefore given in the merger representation. Perhaps this is merely a reorganization of the

${ }^{28}$ Pragmatic inference is dubbed 'conscious' in view of the recent debates on the scope of the term 'inference' (see e.g. Recanati 2004). There is no unconscious inference in my model.

${ }^{29}$ It seems that in this way we can also account for metaphor and irony, but this is a project for the future. 
field in order to focus on salience, but I shall not attempt a comparison for the purpose of this paper.

To sum up, we have rejected the assumed priority of the WS source. We have also allowed more power to the sources CPI, SCD and CD, which seems to better reflect the interaction of the pragmatic components of utterance meaning with the logical form than Recanati's free enrichment does. But this comes at the price of redrawing the boundary between what is said and what is implicated and abandoning the development of the logical form as the defining characteristic of what is said. In other words, what is said may not always be a development of the logical form of the sentence, but on some (rare) occasions it can have an altogether different form. For example, (30a) can now have, say, (30b) as its primary utterance meaning, rather than (30c).

(30a) Mother to a little boy, crying over a cut finger: 'You are not going to die.'

(30b) You shouldn't worry.

(30c) You are not going to die from this wound.

This is a big step, but, it seems, a supportable and promising one. The primary meaning (what is said, what is explicit, etc.) need not be partially isomorphic with the linguistic meaning. Pace post-Gricean attempts to draw the boundary, best summarized in Carston (1988) and Recanati (1989), there is no compelling reason to make this restriction. If we take this step, then new possibilities open up concerning solutions to the problems with intensional contexts, metaphorical expressions, irony, and other stumbling blocks for semantic theory. The main strength of this reanalysis is that we obtain a more accurate account of the composition of meaning. It seems that this is how we should conceive of compositionality. If the output of the four sources of meaning (WS, CPI, CD, and SCD) merges to produce a meaning representation (merger representation), then it is only natural to require the merger representation, rather than the output of grammar (WS), to be compositional. Such pragmatics-rich compositionality would be considered highly controversial in some formal semantics circles, but is gaining ground in post-Gricean views on meaning construction. ${ }^{30}$ The next step will be to construct an algorithm that would capture the interaction of the sources of meaning identified in the theory.

\footnotetext{
${ }^{30}$ The above proposal is compatible with, and can be regarded as an execution of, Recanati's observation:

"...the semantics of natural language is not insulationist. (...)[T] he meaning of the whole is not constructed in a purely bottom-up manner from the meanings of the parts. The
} 
K. M. Jaszczolt: Varieties of Defaults

\section{Concluding remarks}

The objective of this enquiry was not to provide a rigid classification of defaults or to match types of expressions with types of defaults. Instead, it was to point out that before we continue the disputes concerning the adequacy of the 'default model' of utterance interpretation, it is necessary to scrutinize the use of the term 'default' in the literature, and then provide definitional characteristics, as far as it is possible, of such default meanings. First, I pointed out that there are considerable differences in the understanding of the term 'default' in the literature. Further, I demonstrated that the seminal topics for defining defaults are (i) the question as to whether defaults and pragmatic inference are compatible, and (ii) the specification of the unit on which default enrichment operates, that is, the question whether defaults can be local, pre-propositional, as well as global, post-propositional. Next, I attempted a classification of default interpretations, resolving to accept strong, cognitive defaults, and somewhat less clear-cut social and cultural defaults, but reject the putative categories of physical and lexical defaults. Finally, I sketched some principles on which a compositional theory of utterance meaning that incorporates meaning information from such defaults can be founded. It can be gleaned from my discussion of the properties of default interpretations that 'default', for the purpose of pragmatic theory, is at present best understood rather loosely to mean 'salient interpretation'. The exact properties, listed as D1-D7 in Section 1.7, are still a matter of controversy. If this is the case, then the polarisation of the post-Gricean field may easily give way to more consensus. There are salient interpretations, as we all agree, but the answer as to how they are arrived at may prove to borrow insights from both sides: the advocates of strong, defeasible and local defaults like Levinson and the advocates of inference, like relevance theorists. The thoughts and arguments in this paper point to the possible utility of such a middle way, concluding that, at least, it is worth exploring.

\section{References}

Asher, N. and A. Lascarides (1995). Lexical disambiguation in a discourse context. Journal of Semantics 12: 69-108.

Asher, N. and A. Lascarides (2003). Logics of Conversation. Cambridge: Cambridge University Press.

meaning of the whole is influenced by top-down, pragmatic factors, and through the meaning of the whole the meanings of the parts are also affected. So we need a more 'interactionist' or even 'Gestaltist' approach to compositionality." Recanati (2004: 132). 
Bach, K. (1984). Default reasoning: Jumping to conclusions and knowing when to think twice. Pacific Philosophical Quarterly 65: 37-58.

Bach, K. (1987a). Thought and Reference. Oxford: Clarendon Press.

Bach, K. (1987b). On communicative intentions: A reply to Recanati. Mind and Language 2: 141-154.

Bach, K. (1994). Semantic slack: What is said and more. In: S.L. Tsohatzidis (ed.), Foundations of Speech Act Theory: Philosophical and Linguistic Perspectives. London: Routledge. 267-291.

Bach, K. (1995). Remark and reply. Standardization vs. conventionalization. Linguistics and Philosophy 18: 677-686.

Bach, K. (1998). Postscript (1995): Standardization revisited. In: A. Kasher (ed.), Pragmatics: Critical Concepts. Vol. 4. London: Routledge. 712722.

Benferhat, S., J. F. Bonnefon and R. da Silva Neves (2005). An overview of possibilistic handling of default reasoning, with experimental studies. Synthese 146: 53-70.

Bezuidenhout, A. L. and R. K. Morris (2004). Implicature, relevance and default pragmatic inference. In: I. A. Noveck and D. Sperber (eds.), Experimental Pragmatics. Basingstoke: Palgrave Macmillan. 257-282.

Blutner, R. (2000). Some aspects of optimality in natural language interpretation. Journal of Semantics 17: 189-216.

Blutner, R. and H. Zeevat (2004). Editors' introduction: Pragmatics in Optimality Theory. In: R. Blutner and H. Zeevat (eds.), Optimality Theory and Pragmatics. Basingstoke: Palgrave Macmillan. 1-24.

Bultinck, B. (2005). Numerous Meanings: The Meaning of English Cardinals and the Legacy of Paul Grice. Oxford: Elsevier.

Cappelen, H. and E. Lepore. (2005). Insensitive Semantics: A Defense of Semantic Minimalism and Speech Act Pluralism. Oxford: Blackwell.

Carston, R. (1988). Implicature, explicature, and truth-theoretic semantics. In: R. M. Kempson (ed.), Mental Representations: The Interface Between Language and Reality. Cambridge: Cambridge University Press. 155181.

Carston, R. (1998a). Postscript (1995) to Carston 1988. In: A. Kasher (ed.), Pragmatics: Critical Concepts. Vol. 4. London: Routledge. 464-479. 
K. M. Jaszczolt: Varieties of Defaults

Carston, R. (1998b). Informativeness, relevance and scalar implicature. In: R. Carston and S. Uchida (eds.), Relevance Theory: Applications and Implications. Amsterdam: J. Benjamins. 179-236.

Carston, R. (2001). Relevance Theory and the saying/implicating distinction. UCL Working Papers in Linguistics 13: 1-34.

Carston, R. (2002a). Thoughts and Utterances: The Pragmatics of Explicit Communication. Oxford: Blackwell.

Carston, R. (2002b). Linguistic meaning, communicated meaning and cognitive pragmatics. Mind and Language 17: 127-148.

Chierchia, G. (2004). Scalar implicatures, polarity phenomena, and the syntax/pragmatics interface. In: A. Belletti (ed.), Structures and Beyond: The Cartography of Syntactic Structures, vol. 3. Oxford: Oxford University Press. 39-103.

Chierchia, G., M. T. Guasti, A. Gualmini, L. Meroni, S. Crain and F. Foppolo (2004). Semantic and pragmatic competence in children's and adults' comprehension of or. In: I. A. Noveck and D. Sperber (eds.), Experimental Pragmatics. Basingstoke: Palgrave Macmillan. 283-300.

Damasio, A. R. (1999). How the brain creates the mind. Scientific American, December 1999: 74-79.

Fodor, J. A. (1994). The Elm and the Expert: Mentalese and Its Semantics. Cambridge, Mass.: MIT Press.

Geurts, B. (1998). The mechanisms of denial. Language 74: 274-307.

Grice, H. P. (1975). Logic and conversation. In: P. Cole and J. L. Morgan (eds.), Syntax and Semantics. Vol. 3. New York: Academic Press. Reprinted in: H. P. Grice. 1989. Studies in the Way of Words. Cambridge, Mass.: Harvard University Press. 22-40.

Horn, L. R. (1984). Toward a new taxonomy for pragmatic inference: Q-based and R-based implicature. In: D. Schffrin (ed.), Georgetown University Round Table on Languages and Linguistics 1984. Washington, D.C.: Georgetown University Press. 11-42.

Horn, L. R. (1988). Pragmatic theory. In: F. J. Newmeyer (ed.), Linguistics: The Cambridge Survey. Vol. 1. Cambridge: Cambridge University Press. 113-145.

Horn, L. R. (1992). The said and the unsaid. Ohio State University Working Papers in Linguistics 40 (SALT II Proceedings). 163-192.

Horn, L. R. (2004). Implicature. In: L. R. Horn and G. Ward (eds.), The Handbook of Pragmatics. Oxford: Blackwell. 3-28. 
Horn, L. R. (2006). The border wars: A neo-Gricean perspective. In: K. von Heusinger and K. Turner (eds.), Where Semantics Meets Pragmatics: The Michigan Papers. Oxford: Elsevier. 21-48.

Jackendoff, R. (1990). Semantic Structures. Cambridge, Mass.: MIT Press.

Jackendoff, R. (1991). Parts and boundaries. Cognition 41. Reprinted in: B. Levin and S. Pinker (eds.), Lexical and Conceptual Semantics. Oxford: Blackwell. 9-45.

Jaszczolt, K. M. (1997). The Default De Re Principle for the interpretation of belief utterances. Journal of Pragmatics 28: 315-336.

Jaszczolt, K. M. (1998a). Reports on beliefs: Default interpretations and default intentions. Journal of Literary Semantics 27: 31-42.

Jaszczolt, K. M. (1998b). Referring in discourse: Referential intention and the 'taking for granted' principle. Journal of Literary Semantics 27: 96109.

Jaszczolt, K. M. (1999a). Default semantics, pragmatics, and intentions. In: K. Turner (ed.), The Semantics/Pragmatics Interface from Different Points of View. Oxford: Elsevier Science. 199-232.

Jaszczolt, K. M. (1999b). Discourse, Beliefs, and Intentions: Semantic Defaults and Propositional Attitude Ascription. Oxford: Elsevier Science.

Jaszczolt, K. M. (2000). The default-based context-dependence of belief reports. In: K. M. Jaszczolt (ed.), The Pragmatics of Propositional Attitude Reports. Oxford: Elsevier Science. 169-185.

Jaszczolt, K. M. (2002). Semantics and Pragmatics: Meaning in Language and Discourse. London: Longman.

Jaszczolt, K. M. (2005). Default Semantics: Foundations of a Compositional Theory of Acts of Communication. Oxford: Oxford University Press.

Jaszczolt, K. M. (2006). Meaning merger: Pragmatic inference, defaults, and compositionality. Intercultural Pragmatics 3: 195-212.

Koenig, J.-P. (1993). Scalar predicates and negation: Punctual semantics and interval interpretations. Chicago Linguistic Society 27. Part 2: The Parasession on Negation. 140-155.

Landman, F. (2000). Events and Plurality. Dordrecht: Kluwer.

Lascarides, A. and A. Copestake (1998). Pragmatics and word meaning. Journal of Linguistics 34: 387-414.

Levinson, S. C. (1987). Minimization and conversational inference. In: J. Verschueren and M. Bertuccelli-Papi (eds.), The Pragmatic Perspective. 
K. M. Jaszczolt: Varieties of Defaults

Selected Papers from the 1985 International Pragmatics Conference. Amsterdam: J. Benjamins. 61-129.

Levinson, S. C. (1995). Three levels of meaning. In: F. R. Palmer (ed.), Grammar and Meaning. Essays in Honour of Sir John Lyons. Cambridge: Cambridge University Press. 90-115.

Levinson, S. C. (2000). Presumptive Meanings: The Theory of Generalized Conversational Implicature. Cambridge, Mass.: MIT Press.

Levinson, S.C. (2003). Space in Language and Cognition: Explorations in Cognitive Diversity. Cambridge: Cambridge University Press.

Lyons, W. (1995). Approaches to Intentionality. Oxford: Clarendon Press.

Musolino, J. (2004). The semantics and acquisition of number words: Integrating linguistic and developmental perspectives. Cognition 93: $1-41$.

Noveck, I. A. (2001). When children are more logical than adults: Experimental investigations of scalar implicature. Cognition 78: 165188.

Noveck, I. A. (2004). Pragmatic inferences related to logical terms. In: I. A. Noveck and D. Sperber (eds.), Experimental Pragmatics. Basingstoke: Palgrave Macmillan. 301-321.

Noveck, I. A. and D. Sperber (eds.) (2004). Experimental Pragmatics. Basingstoke: Palgrave Macmillan.

Papafragou, A. and J. Musolino (2003). Scalar implicatures: Experiments at the semantics-pragmatics interface. Cognition 86: 253-282.

Pelletier, F. J. and R. Elio (2005). The case for psychologism in default and inheritance reasoning. Synthese 146: 7-35.

Prince, A. and P. Smolensky (2004). Optimality Theory: Constraint Interaction in Generative Grammar. Oxford: Blackwell.

Recanati, F. (1989). The pragmatics of what is said. Mind and Language 4. Reprinted in: S. Davis (ed.) (1991) Pragmatics: A Reader. Oxford: Oxford University Press. 97-120.

Recanati, F. (2002). Does linguistic communication rest on inference?. Mind and Language 17: 105-126.

Recanati, F. (2003). Embedded implicatures. http://jeannicod.ccsd.cnrs. $\mathrm{fr} /$ documents.

Recanati, F. (2004). Literal Meaning. Cambridge: Cambridge University Press. 
Recanati, F. (2005). Literalism and contextualism: Some varieties. In: G. Preyer and G. Peter (eds.), Contextualism in Philosophy: Knowledge, Meaning, and Truth. Oxford: Clarendon Press. 171-196.

Reiter, R. (1980). A logic for default reasoning. Artificial Intelligence 13: 81-132.

Saul, J. M. (2002). What is said and psychological reality; Grice's project and relevance theorists' criticisms. Linguistics and Philosophy 25: 347372.

Smolensky, P. (1986). Information processing in dynamical systems: Foundations of Harmony Theory. In: D. E. Rumelhart, J. L. McClelland, and the PDP Research Group (eds.), Parallel Distributed Processing: Explorations in the Microstructure of Cognition, vol. 1. Cambridge, Mass.: MIT Press. 194-281.

Sperber, D. and D. Wilson. (1995). Relevance: Communication and Cognition. Oxford: Blackwell. Second edition.

Talmy, L. (1985). Lexicalization patterns: Semantic structure in lexical forms. In: T. Shopen (ed.), Language Typology and Syntactic Description. Vol. 3. Grammatical Categories and the Lexicon. Cambridge: Cambridge University Press. 57-149.

Talmy, L. (2000). Toward a Cognitive Semantics (2 volumes). Cambridge, Mass.: MIT Press.

Thomason, R. H. (1997). Nonmonotonicity in linguistics. In: J. van Benthem and A. ter Meulen (eds.), Handbook of Logic and Language. Oxford: Elsevier Science. 77-831.

Traugott, E. C. (1999). The role of pragmatics in semantic change. In: J. Verschueren (ed.), Pragmatics in 1998: Selected Papers from the $6^{\text {th }}$ International Pragmatics Conference, vol. 2. Antwerp: International Pragmatics Association. 93-102.

Traugott, E. C. and R. B. Dasher (2002). Regularity in Semantic Change. Cambridge: Cambridge University Press.

Veltman, F. (1996). Defaults in update semantics. Journal of Philosophical Logic 25: 221-261.

Zeevat, H. (2000). Demonstratives in discourse. Journal of Semantics 16: 279-313.

Zeevat, H. (2004). Particles: Presupposition triggers, context markers or speech act markers. In: R. Blutner and H. Zeevat (eds.), Optimality Theory and Pragmatics. Basingstoke: Palgrave Macmillan. 91-111. 